\title{
Gender differences regarding body image, stress and coping strategies in adolescence
}

Camelia Soponaruํㅗ Ancuta Bojian ${ }^{1}$, Magdalena lorga ${ }^{2}$

\author{
${ }^{1}$ Department of Psychology, Faculty of Psychology and Educational Sciences, \\ University "Al.I. Cuza" of Iasi, Romania \\ 2Department of Behavioral Sciences, University of Medicine and Pharmacy \\ "Gr.T. Popa” of lasi, "St. Maria” Child Hospital, Iasi, Romania
}

Submitted: 18 April 2016

Accepted: 9 May 2016

Arch Med Sci Civil Dis 2016; 1: e36-e42

DOI: 10.5114/amscd.2016.59897

Copyright @ 2016 Termedia \& Banach

\section{Abstract}

Introduction: The purpose of the study is to identify the level of stress among adolescents regarding the body image and the strategies that they use to cope with it.

Material and methods: Two hundred and eighty-two adolescents in $10^{\text {th }}$ and $11^{\text {th }}$ grade completed three questionnaires: the Adolescent Stress Questionnaire (ASQ), the Body Image Coping Strategies Inventory (BICSI) and the Body Esteem Scale for Adolescents and Adults (BES).

Results: In the order of results, factors generating stress in adolescents are: money pressure $(M=5.80 \pm 2.70)$, uncertain future $(M=3.02 \pm 1.00)$, school/ leisure conflicts $(M=2.77 \pm 0.96)$, school performance $(M=2.60 \pm 0.74)$, assuming adult responsibilities $(M=2.53 \pm 1.23)$, school attendance $(M=2.52$ $\pm 0.96)$, romantic relationships $(M=2.51 \pm 1.04)$, home life $(M=2.31 \pm 0.74)$, interactions with teachers $(M=2.22 \pm 0.80)$ and peer pressure $(M=2.15 \pm 0.83)$. Girls are more stressed by home life, peer pressure, an uncertain future, money pressure and adult responsibilities, while boys obtained higher values in the variable stress generated by school attendance. The most frequently used coping mechanism is positive rational acceptance $(M=2.52 \pm 0.64)$.

Conclusions: The level of stress among adolescents correlates with the level of satisfaction regarding the body image.

Key words: body image, coping mechanisms, stress, adolescence, boys, girls.

\section{Introduction}

Adolescence is the age most strongly influenced by rapid and potentially damaging changes [1, 2]. This hold true not only for biological development, where changes are highly obvious, but equally for cognitive and psychosocial maturing. While transition through adolescence is inevitable, the speed and magnitude of these changes overload many people's coping abilities, thus resulting in the well-known stress of adolescence [3].

Experiencing stress is uncomfortable regardless of age, but what is extremely important is its capacity to affect the individual's health. For adolescents, there is ample evidence proving that stress is connected with the emergence of psychiatric symptomatology, including depression $[4,5]$, suicidal ideation [2] and even the real risk of suicide [4]. But these

\author{
Corresponding author: \\ Magdalena lorga \\ Department \\ of Behavioral Sciences \\ University of Medicine \\ and Pharmacy \\ "Gr.T. Popa" of Iasi \\ "St. Maria" Child Hospital \\ 7 Universitatii St \\ 700460 Iasi, Romania \\ Phone: 0040722800936 \\ E-mail: magdaiorga@yahoo. \\ com
}


are not the only effects which stress may have on adolescents; it is systematically associated with the failure to fight obesity [6], physical inactivity [1] and early consumption of alcohol and tobacco. In any stressful situation, we have at our disposal various coping strategies. These coping strategies refer to the psychological efforts people make to dominate, tolerate, decrease or minimize stressful events [7]. The effects of coping strategies depend on the individual's characteristics, on specifics of the stressor and on contextual demands.

The concept of body image is made of two dimensions, that is, the attitudinal and the perceptual dimension. The attitudinal aspect is reflected by people's positive or negative feelings about their body, in other words, by how satisfied they are with their physical self. The perceptual component is linked to the accuracy of people's estimations of their body size; in other words, it represents the discrepancy between individuals' real and subjectively estimated body dimensions [8]. Research to date emphasizes the fact that disorders may occur in both dimensions, especially among adolescents and young people, these being considered vulnerable to the emergence of body image issues [9].

When a person encounters a situation which threatens his/her body image, he/she will develop and use cognitive and behavioral strategies in order to adapt to or face these stress-generating thoughts, feelings and situations. Despite the fact that there is an extensive literature on coping strategies used by people in threatening situations, few studies have looked into the strategies used by individuals when their body image is under threat. Most studies on body image coping have been directed toward people disfigured by burns [10] or women diagnosed with breast cancer [11, 12].

A unique aspect of body image coping may be its ubiquity. Some individuals resort to certain coping strategies after their body image has been threatened one single time by a certain event, while others use these strategies regularly, due to bodily dissatisfaction. Research has highlighted the fact that women struggling with the stigma of obesity frequently use body image coping strategies [13].

The three coping strategies for body image are: a) Fixation on appearance, consisting of the person's efforts to change or hide those parts of the body perceived as unpleasant, simultaneously engaging in activities aimed at improving physical appearance; b) Avoidance: when this coping strategy is used, the person makes efforts to avoid situations, thoughts or feelings deemed a threat to body image. This person will overeat, will avoid social contacts and will not look at himself in the mirror; c) Positive rational acceptance: the person who adopts this strategy when sensing that his body image is under threat will perform mental and behavioral activities focusing on self-care and will accept his body and experiences in a positive and rational manner. In most cases, the person will tell himself that this negative situation will pass, that it is irrational and that, in reality, he looks better than he feels.

The effect of body image on life satisfaction among adolescents has been revealed by numerous studies, showing that dissatisfaction with the image of their physical appearance can lead to difficulties in social integration, eating disorders, avoidance behaviors or suicides [14-17]. Body image and self-esteem levels are frequently associated with socio-cultural factors, and correlations between use of the internet, preoccupation with self photos, parental and peers factors and the thin models promoted by the media have been identified [18-21]. Body image misperception has important consequences for future adult life, especially among female subjects.

The present study identifies the level of stress associated with body image and the strategies used to cope with it among teenagers in Romania. Differences between boys and girls are presented regarding factors of stress and coping mechanisms.

\section{Material and methods}

The purpose of the research was to identify the differences between boys and girls in the level of stress experienced, the coping strategies used and body image differences.

The group of subjects comprised 282 participants aged from 15 to 19; 114 were boys and 168 were girls. Of the 114 boys, 41 were $10^{\text {th }}$ grade students and 73 were $11^{\text {th }}$ grade students. Of the 168 girls, 70 were $10^{\text {th }}$ grade students and 98 were $11^{\text {th }}$ grade students.

The instruments used were the following:

1. The Adolescent Stress Questionnaire (ASQ), created and validated by Byrne, Davenport and Mazanov in 2007 [3] comprising 55 items in the form of statements referring to stressful situations which adolescents may experience $(\alpha=$ 0.93). The questionnaire highlights the following dimensions: stress generated by home life, school performance, school attendance, romantic relationships, peer pressure, interactions with teachers, uncertain future, school/leisure conflicts, money pressure and assuming adult responsibilities.

2. The Body Image Coping Strategies Inventory, validated and published by Cash, Santos and Williams in 2005 [22], which identifies coping strategies used by adolescents to deal with situations which threaten their body image $(\alpha=0.89)$. The 29 items of the questionnaire 
assess three coping strategies: fixation on appearance, positive rational acceptance and avoidance.

3. The Body Esteem Scale for Adolescents (BES) by Mendelson et al., 2001 [23], evaluates the extent to which adolescents are satisfied with their body image. The 21 items of this scale measure the way in which adolescents assess their weight, the extent to which they consider that they obtain advantages from their weight and the way in which they assess their physical appearance. The scales of this instrument obtained an appropriate alpha coefficient ( $\alpha=0.89$ ).

The research was carried out from April to May 2014, in colleges from North-Eastern Romania. School principals gave their consent and teachers who would allow the questionnaires to be completed during class were identified. All participants in this research received the informed consent indications, which clearly explained the concept of body image. In addition, information was offered on answer options, and the fact that data privacy is guaranteed was emphasized. The time to fill in the questionnaire was unlimited.

\section{Statistical analysis}

The demographic data requested of participants were: grade, age, gender and the high school where they were enrolled. The data obtained were processed by SPSS 17 software.

\section{Results}

\section{Body image and gender differences}

The data obtained from the statistical processing of the Body Image Coping Strategies Inventory regarding body image, using the $t$ test for the comparison of means in the variable "satisfaction with body image", depending on the gender variable, show statistically significant differences ( $p=0.001$ ) between the mean obtained by male subjects $(M=75.01)$ in the variable "satisfaction with body image" and the mean obtained by female subjects $(M=69.20)$, in that male subjects are more satisfied with their body image than female subjects.

\section{Stress and gender differences}

In order to identify the dimensions toward which adolescents feel the highest level of stress, we created new variables, calculating the mean of items for each scale of the instrument, constituting each dimension of the Adolescent Stress Questionnaire (ASQ).

The factor exerting the highest level of stress on adolescents is money pressure $(M=5.80, S D=$
2.70), followed by an uncertain future $(M=3.02$, $S D=1.00)$, school/leisure conflicts $(M=2.77$, $\mathrm{SD}=0.96)$, school performance $(M=2.60, \mathrm{SD}$ $=0.74)$, assuming adult responsibilities $(M=$ $2.53, \mathrm{SD}=1.23)$, school attendance $(M=2.52$, $\mathrm{SD}=0.96)$, romantic relationships $(M=2.51, \mathrm{SD}=$ 1.04), home life $(M=2.31, S D=0.74)$, interactions with teachers $(M=2.22, S D=0.80)$ and peer pressure $(M=2.15, S D=0.83)$.

In order to highlight differences related to body image between subjects with a higher level of stress and those with a lower level, the total stress score was calculated and divided, by the median test, into two levels, namely "high" and "low". After applying the $t$ test for independent samples, we obtained significant differences $(\mathrm{t}(280)=2.00$, $p=0.046$ ), in that subjects with a low level of stress had a higher level of satisfaction regarding the body image $(M=73.24)$, compared to subjects with a high level of stress $(M=69.79)$.

The research aimed at emphasizing gender differences regarding the stress variable and the coping mechanisms used.

To identify the relation between the two variables (stress and gender), the $t$ test for independent samples was used. The results reveal a significant difference ( $T=2.361, p=0.019)$ between the mean obtained by male subjects $(M=130.91)$ in the stress variable and that obtained by female subjects $(M=140.55)$, in that girls tend to perceive a higher level of stress, compared to boys. The results are presented in Table I.

The results indicate that stressors are different depending on gender. In female subjects, the following were identified as stress-generating factors: home life, peer pressure, an uncertain future, money pressure and adult responsibilities, while in male subjects, significantly higher values were obtained in the variable "stress generated by school attendance".

\section{Coping strategies and gender differences}

The coping mechanism most frequently used by the adolescents included in the study is positive rational acceptance $(M=2.52 \pm 0.64)$, followed by fixation on appearance $(M=2.43 \pm 0.64)$ and by avoidance as a coping mechanism ( $M=$ $1.19 \pm 0.51$ ). No differences were identified in the frequency of use of these coping mechanisms according to gender. Female subjects predominantly use the following coping mechanisms: positive rational acceptance $(M=2.63 \pm 0.68)$, fixation on appearance $(M=2.56 \pm 0.61)$ and avoidance $(M=1.96 \pm 0.50)$, and male subjects predominantly use the following coping mechanisms: positive rational acceptance $(M=2.36 \pm 0.58)$, followed by fixation on appearance $(M=0.23 \pm 0.65)$ and by avoidance $(M=1.90 \pm 0.51)$. 
Table I. Gender differences regarding stress factors

\begin{tabular}{|c|c|c|c|c|c|c|}
\hline Stress factors & $N$ & Mean & SD & $t$ & $\mathrm{~d} f$ & $P$-value \\
\hline Home life: & & & & -3.143 & 280 & 0.002 \\
\hline Male & 114 & 27.98 & 8.66 & & & \\
\hline Female & 168 & 31.62 & 10.10 & & & \\
\hline School results: & & & & -0.804 & 234.513 & 0.422 \\
\hline Male & 114 & 17.96 & 5.34 & & & \\
\hline Female & 168 & 18.47 & 5.08 & & & \\
\hline School attendance: & & & & 2.772 & 234.543 & 0.006 \\
\hline Male & 114 & 10.86 & 3.91 & & & \\
\hline Female & 168 & 9.57 & 3.72 & & & \\
\hline Romantic relationship: & & & & -1.820 & 280 & 0.070 \\
\hline Male & 114 & 11.89 & 4.63 & & & \\
\hline Female & 168 & 13.04 & 5.57 & & & \\
\hline Peer pressure: & & & & -2.902 & 262.771 & 0.004 \\
\hline Male & 114 & 13.91 & 5.30 & & & \\
\hline Female & 168 & 15.89 & 6.06 & & & \\
\hline Interaction with teachers: & & & & -1.015 & 263.375 & 0.311 \\
\hline Male & 114 & 15.16 & 5.13 & & & \\
\hline Female & 168 & 15.83 & 5.90 & & & \\
\hline Uncertain future: & & & & -3.962 & 248.374 & $<0.001$ \\
\hline Male & 114 & 8.23 & 2.88 & & & \\
\hline Female & 168 & 9.64 & 2.98 & & & \\
\hline School/leisure conflicts: & & & & 0.242 & 247.798 & 0.809 \\
\hline Male & 114 & 16.72 & 5.67 & & & \\
\hline Female & 168 & 16.55 & 5.85 & & & \\
\hline Money pressure: & & & & -2.149 & 249.592 & 0.033 \\
\hline Male & 114 & 5.39 & 2.61 & & & \\
\hline Female & 168 & 6.08 & 2.73 & & & \\
\hline Assuming adult responsibilities: & & & & -2.336 & 280 & 0.020 \\
\hline Male & 114 & 2.32 & 1.12 & & & \\
\hline Female & 168 & 2.67 & 1.29 & & & \\
\hline
\end{tabular}

Table II. Results in the $t$ test for comparing means in coping mechanism variables fixation on appearance, positive rational acceptance and avoidance, according to the gender variable

\begin{tabular}{|c|c|c|c|c|c|c|}
\hline Variable & $N$ & Mean & SD & $t$ & $\mathrm{~d} f$ & $P$-value \\
\hline Fixation on appearance: & & & & -4.293 & 230.359 & $<0.001$ \\
\hline Male & 114 & 2.23 & 0.65 & & & \\
\hline Female & 168 & 2.56 & 0.61 & & & \\
\hline Positive rational acceptance: & & & & -3.847 & 280 & $<0.001$ \\
\hline Male & 114 & 2.25 & 0.45 & & & \\
\hline Female & 168 & 2.45 & 0.41 & & & \\
\hline Avoidance: & & & & -1.361 & 236.433 & 0.175 \\
\hline Male & 114 & 1.89 & 0.49 & & & \\
\hline Female & 168 & 1.97 & 0.47 & & & \\
\hline
\end{tabular}


The $t$ tests for independent samples emphasized the existence of statistically significant differences between female and male subjects in fixation on appearance as a coping mechanism, girls using it more often. The obtained results are presented in Table II.

The same tendency may be noted for positive rational acceptance as a coping mechanism, female participants obtaining a significantly higher mean than male subjects in the studied dependent variable. Regarding avoidance as a coping mechanism, no statistically significant differences could be identified between means obtained by the two genders.

To identify the interaction effect between the gender variable and the stress variable on body image and the interaction effect between the gender variable and the coping mechanisms variable on body image, the univariate ANOVA method was used. The results obtained show no interaction effect of the variables gender and stress which acts at the level of the dependent variable body image, $F(1,281)=0.163, p=0.687$, just as there is no interaction effect of the variables gender and coping mechanism which acts at the level of the dependent variable body image, $F(2,281)=$ 2.772, $p=0.064$.

\section{Correlations between research variables:}

stress, body image and coping mechanisms

In order to find out if there is an association between the variables of this research, we calculated the Pearson correlation coefficients. We found that stress correlates positively and weakly with: fixation on appearance $(r=0.252, p<0.001)$, positive rational acceptance $(r=0.253, p<0.001)$, avoidance $(r=0.249, p<0.001)$; and negatively with body image (the total score for BES) $(r=$ $-0.183, p=0.002$ )
The coping strategy fixation on appearance correlates negatively with body image (the total score for BES) $(r=-0.405, p<0.001)$, and the avoidance coping strategy correlates negatively with body image (the total score obtained for BES) $(r=-0.215, p<0.001)$.

\section{Predictive power of the model made} of the predictors stress and the coping mechanisms fixation on appearance, positive rational acceptance and avoidance

Table III presents results regarding coping strategies and stress among adolescents.

The predictive model made of the predictors fixation on appearance, positive rational acceptance, avoidance and stress is statistically significant $(p<0.001)$ and explains $18.9 \%$ of the variance of the body image criteria.

Stress within this model is statistically insignificant. Fixation on appearance and the avoidance coping mechanism are negative predictors, while positive rational acceptance is a positive predictor.

Identification, among the three coping mechanisms, of significant predictors of the body image criterion

To achieve this objective, three simple linear regressions were performed, identifying the following results for the three types of coping presented in Table IV.

The predictor fixation on appearance explains $16.4 \%$ of the proportion of the body image criterion, this being a negative predictor. The avoidance coping mechanism explains $4.6 \%$ of the variance of the body image criterion, being a negative predictor.

Table III. Coping strategies and stress

\begin{tabular}{|lccccccc|}
\hline Variable & $R$ & $R^{2}$ & $\beta$ & $b$ & SE $b$ & $F$ & $P$-value \\
\hline & 0.434 & 0.189 & & & & 16.105 & $<0.001$ \\
\hline $\begin{array}{l}\text { Fixation on } \\
\text { appearance }\end{array}$ & & & -0.414 & -9.267 & 1.351 & & $<001$ \\
\hline $\begin{array}{l}\text { Positive rational } \\
\text { acceptance }\end{array}$ & & 0.138 & 4.534 & 2.150 & & 0.036 \\
\hline Avoidance & & & -0.155 & -4.672 & 1.861 & 0.013 \\
\hline Stress & & -0.029 & -0.849 & 1.661 & 0.610 \\
\hline
\end{tabular}

Table IV. Regression analysis aimed at assessing body image based on the coping mechanism variables

\begin{tabular}{|lccccccc|}
\hline Coping mechanism & $\boldsymbol{R}$ & $\boldsymbol{R}^{\mathbf{2}}$ & $\boldsymbol{B}$ & $\boldsymbol{b}$ & $\mathrm{SE} \boldsymbol{b}$ & $\boldsymbol{F}$ & $\boldsymbol{P}$-value \\
\hline Fixation on appearance & 0.405 & 0.164 & -0.405 & -9.066 & 1.223 & 54.979 & $<0.001$ \\
\hline $\begin{array}{l}\text { Positive rational } \\
\text { acceptance }\end{array}$ & 0.115 & 0.013 & -0.115 & -3.787 & 1.955 & 3.753 & 0.054 \\
\hline Avoidance & 0.215 & 0.046 & -0.215 & -6.514 & 1.764 & 13.632 & $<0.001$ \\
\hline
\end{tabular}


Table V. Regression analysis aimed at assessing body image based on stressor variables

\begin{tabular}{|lccccccc|}
\hline Coping mechanism & $R$ & $R^{2}$ & $\beta$ & $b$ & SE $\boldsymbol{b}$ & $\boldsymbol{F}$ & $\boldsymbol{P}$-value \\
\hline Home life & 0.145 & 0.021 & -0.145 & -0.217 & 0.089 & 6.006 & 0.015 \\
\hline School results & 0.156 & 0.024 & -0.156 & -0.438 & 0.165 & 7.013 & 0.009 \\
\hline School attendance & 0.005 & 0.000 & 0.005 & 0.018 & 0.226 & 0.007 & 0.935 \\
\hline Romantic relationship & 0.082 & 0.007 & -0.082 & -0.228 & 0.165 & 1.906 & 0.169 \\
\hline Peer pressure & 0.267 & 0.071 & -0.267 & -0.664 & 0.143 & 21.495 & $<0.001$ \\
\hline $\begin{array}{l}\text { Interaction with } \\
\text { teachers }\end{array}$ & 0.090 & 0.008 & -0.090 & -0.234 & 0.154 & 2.307 & 0.130 \\
\hline Uncertain future & 0.142 & 0.020 & -0.142 & -0.682 & 0.285 & 5.731 & 0.017 \\
\hline School/leisure conflicts & 0.024 & 0.001 & -0.024 & -0.061 & 0.150 & 0.163 & 0.686 \\
\hline Money pressure & 0.226 & 0.051 & -0.226 & -1.216 & 0.313 & 15.061 & $<0.001$ \\
\hline $\begin{array}{l}\text { Assuming adult } \\
\text { responsibilities }\end{array}$ & 0.093 & 0.009 & -0.093 & -1.089 & 0.699 & 2.426 & 0.120 \\
\hline
\end{tabular}

\section{Identification of stressors which are} significant predictors of body image

Some stressors are more significant predictors than others as regards body image satisfaction. The results are presented in Table V.

Of the 10 predictors, the following 5 are significant for the body image criterion: home life: explains $2.1 \%$ of the body image variance, being a negative predictor; school performance: explains $2.4 \%$ of the criterion variance, being a negative predictor; peer pressure: explains $7.1 \%$ of the criterion variance, being a negative predictor; uncertain future: $2.0 \%$ of the criterion variance, being a negative predictor; money pressure: $5.1 \%$ of the body image variance, being a negative predictor.

\section{Discussion}

The results of the research on body image and gender differences correlate with the data in the literature. Gender is a key moderator within research aimed at studying stress and the body image among adolescents. In general, women report a level of body dissatisfaction and stress twice as high as that reported by men [24]. Thus, gender influence on both the body image and the perceived level of stress is increasingly obvious, representing a variable to be taken into account in this study as well.

Influenced by Western cultural ideals, women want a slim and graceful body, experiencing stress because of family, friends and romantic relationships. At the same time, men make efforts to have a muscular body, being stressed due to aspects relevant to themselves and due to non-interpersonal contexts [25].

It is important to point out that, following the performed research, it was found that a low level of stress is associated with satisfaction with the body image, a balanced, healthy diet and the feeling of control over one's body weight, both in girls and in boys. By noticing how important stress is in the life of adolescents and how it affects their body image, we can act in order to prevent the emergence of body image disorders and eating disorders, which claim more and more victims among adolescents.

The most stressful factors for adolescents are money pressure and an uncertain future, and the last places are taken by interactions with teachers and peer pressure. Subjects with a low level of stress have higher satisfaction with body image, compared to subjects with a high level of stress.

Concerning gender differences, the study showed that girls tend to perceive a higher level of stress compared to boys, the former obtaining significantly higher values than male subjects in the following stressors: home life, peer pressure, uncertain future, money pressure and adult responsibilities. Boys obtained significantly higher values than girls in the variable stress generated by school attendance. Moreover, girls resort to fixation on appearance and positive rational acceptance as coping mechanisms more frequently, as regards the body image. In general, male subjects are more satisfied with their body image than female subjects.

Stress correlates positively and weakly with coping strategies (the more prominent the stress, the more present the coping mechanisms) and negatively with the body image (the more prominent the stress, the more dissatisfied they are with their body image). The coping strategies fixation on appearance and avoidance correlate negatively with the body image; the more dissatisfied they are with their body image, the greater is the presence of the coping strategies fixation on appearance and avoidance.

From the multitude of predictors which may influence adolescents' body image, the predictive model consisting of the predictors fixation on appearance, positive rational acceptance, avoidance 
and stress explain $18.9 \%$ of the body image criterion variance; fixation on appearance and the avoidance coping mechanism are negative predictors, while positive rational acceptance is a positive predictor.

In conclusion, the most stressful factors generating stress in adolescents are: money pressure, uncertain future, school/leisure conflicts, school performance, assuming adult responsibilities, school attendance, romantic relationships, home life, interactions with teachers and peer pressure. Girls are more stressed by home life, peer pressure, an uncertain future, money pressure and adult responsibilities, while boys are more stressed by school attendance. The most frequently used coping mechanism is positive rational acceptance. The level of stress among adolescents correlates with the level of satisfaction regarding the body image.

\section{Conflict of interest}

The authors declare no conflict of interest.

\section{References}

1. Abbott BD, Barber BL. Differences in functional and aesthetic body image between sedentary girls and girls involved in sports and physical activity: does sport type make a difference? Psychology of Sport and Exercise 2011; 12: 333-42.

2. Beautrais AL. Suicide and serious suicide attempts in youth: a multiple-group comparison study. Am J Psychiatry 2003; 160: 1093-9.

3. Byrne DG, Davenport SC, Mazanov J. Profiles of adolescent stress: the development of the adolescent stress questionnaire (ASQ). J Adolesc 2007; 30: 393-416.

4. Deardorff J, Gonzales NA, Sandler IN. Control beliefs as a mediator of the relation between stress and depressive symptoms among inner-city adolescents. J Abnorm Child Psychol 2003; 31: 205-17.

5. Sawyer SM, Afifi RA, Bearinger LH, et al. Adolescence: a foundation for future health. Lancet 2012; 379: 1630-40

6. Mellin AE, Neumark-Sztainer D, Story M, Ireland M, Resnick MD. Unhealthy behaviors and psychosocial difficulties among overweight adolescents: the potential impact of familial factors. J Adolesc Health 2002; 31: 145-53.

7. Lazarus RS, Folkman S. Stress, appraisal, and coping. Springer 1984.

8. Gardner H. Multiple intelligences: new horizons. Basic Books 2006

9. Mellor D, Fuller-Tyszkiewicz M, McCabe MP, Ricciardelli LA, Skouteris H, Mussap AJ. A test of the resource security and the body mass index reference point hypotheses of body dissatisfaction amongst adolescents in eight countries. Ethnicity Health 2014; 19: 548-64.

10. Fauerbach JA, Heinberg LJ, Lawrence JW, et al. Effect of early body image dissatisfaction on subsequent psychological and physical adjustment after disfiguring injury. Psychosom Med 2000; 62: 576-82.

11. Den Oudsten BL, Van der Steeg AF, Roukema JA, De Vries J. Changes in body image in women with ear- ly stage breast cancer. INTECH Open Access Publisher 2012.

12. Gardikiotis I, lorga M, Sztankovszky LZ, Azoicai D. Sexuality, body image and psychological well-being of patients with mastectomy after breast cancer. Rev Med Chir Soc Nat lasi 2015; 119: 849-55.

13. Myers A, Rosen JC. Obesity stigmatization and coping: relation to mental health symptoms, body image, and self-esteem. Int J Obes 1999; 23: 221-30.

14. Carmona J, Tornero-Quiñones I, Sierra-Robles Á. Body image avoidance behaviors in adolescence: a multilevel analysis of contextual effects associated with the physical education class. Psychol Sport Exercise 2015; 16: 70-8.

15. Flament MF, Hill EM, Buchholz A, Henderson K, Tasca GA, Goldfield G. Internalization of the thin and muscular body ideal and disordered eating in adolescence: the mediation effects of body esteem. Body Image 2012; 9: 68-75.

16. Holsen I, Jones DC, Birkeland MS. Body image satisfaction among Norwegian adolescents and young adults: A longitudinal study of the influence of interpersonal relationships and BMI. Body Image 2012; 9: 201-8.

17. Muehlenkamp JJ, Brausch AM. Body image as a mediator of non-suicidal self-injury in adolescents. J Adolesc 2012; 35: 1-9.

18. Meier EP, Gray J. Facebook photo activity associated with body image disturbance in adolescent girls. Cyberpsychology, Behavior, and Social Networking 2014; 17: 199 206.

19. Michael SL, Wentzel K, Elliott MN, et al. Parental and peer factors associated with body image discrepancy among fifth-grade boys and girls. J Youth Adolesc 2014; 43: 15-29.

20. Rosen JC. Body image disorder: definition, development, and contribution to eating disorders. The etiology of bulimia: the individual and familial context. 2013; 157-77.

21. Tiggemann M, Slater A. NetTweens the Internet and body image concerns in preteenage girls. J Early Adolesc 2014; 34: 606-20.

22. Cash TF, Santos MT, Williams EF. Coping with body-image threats and challenges: validation of the body image coping strategies inventory. J Psychosom Res 2005; 58: 190-9.

23. Mendelson BK, Mendelson MJ, White DR. Body-esteem scale for adolescents and adults. J Personal Assessm 2001; 76: 90-106.

24. Murray KM, Byrne DG, Rieger E. Investigating adolescent stress and body image. J Adolesc 2011; 34: 269-78.

25. Slater A, Tiggemann M. Gender differences in adolescent sport participation, teasing, self-objectification and body image concerns. J Adolesc 2011; 34: 455-63. 